\title{
Orbital cellulitis following silicone-sponge scleral buckles
}

This article was published in the following Dove Press journal:

Clinical Ophthalmology

30 October 2013

Number of times this article has been viewed

\section{Arie Y Nemet \\ Joseph R Ferencz \\ Ori Segal \\ Amit Meshi}

Department of Ophthalmology, Meir Medical Center, Kfar Saba, Israel
Correspondence: Arie Y Nemet Department of Ophthalmology, Meir Medical Center, 59 Tsharnihovski Street, Kfar Saba 44299, Israel

Tel +97252838 6855

Fax+97297472427

Email nemet.arik@gmail.com
Background: Acute or chronic infection of the scleral explant is rare. We report seven cases of scleral explant infections that caused orbital cellulitis.

Materials and methods: This was a retrospective chart review of oculoplastics at oculoplastics and vitreo-retinal units in a secondary referral hospital. All subjects had orbital cellulitis secondary to scleral buckle in the range of January 1990 to March 2010. Demographics, imaging studies, and pathology specimens were reviewed.

Results: A total of 841 silicone-sponge scleral buckle implants for rhegmatogenous retinal detachment were performed. Forty were extracted (4.75\%; annual rate of 1.9 cases). Seven $(0.83 \%)$ had orbital cellulitis. The mean time from implantation to presentation was 5.7 years. There was bacterial growth in all specimens, with Staphylococcus aureus in four.

Conclusions: Patients who are operated on with silicone-sponge scleral buckling for rhegmatogenous retinal detachment sometimes require removal of the implant because of infection. However, the infection rate is low. Patients should be followed in the long term for possible complications.

Keywords: scleral explant infection, scleral buckle, orbital cellulitis, rhegmatogenous retinal detachment

\section{Introduction}

Scleral buckling (SB) with exogenous material is an effective and important method to reattach the retina. ${ }^{1}$ The most common reasons for silicone SB removal include conjunctival or skin extrusion, extraocular infection, intraocular erosion, endophthalmitis, and recurrent detachment. ${ }^{2}$

Retrospective series have reported complications of SB, most commonly extrusion and infection in $1.3 \%-24.4 \%$ of eyes. ${ }^{2,3}$ Once scleral implant infection occurs, orbital infection results. Almost all cases are intractable and require removal of the implant. ${ }^{3,4}$ Drug-resistant bacteria, such as methicillin-resistant Staphylococcus aureus and Pseudomonas aeruginosa, are reported to cause scleral buckle infections. ${ }^{5,6}$ This report is a retrospective review of our patients with intractable scleral explant infection and secondary orbital cellulitis.

\section{Materials and methods}

A retrospective chart review was performed of all cases of orbital cellulitis secondary to silicone-sponge SB (Labtician Ophthalmics, Oakville, ON, Canada) for rhegmatogenous retinal detachment (RRD) between January 1990 and March 2010. All were primary buckles with no vitrectomy. The operations were performed by a 
single surgeon (JRF). A silicone-sponge SB was used for all cases. Inpatient data extracted from patients' files included demographics, ophthalmic history, imaging studies, bacteriology results, and pathologic specimen data.

Surgery was performed under general anesthesia. A $360^{\circ}$ conjunctival peritomy was performed. The four rectus muscles were isolated and grasped for traction. Four preplaced $5 / 0$ nylon mattress sutures were placed in the four quadrants, $6 \mathrm{~mm}$ posterior and $3 \mathrm{~mm}$ anterior to the posterior edge of the most posterior retinal tear, as identified by an indirect ophthalmoscope. A $7.5 \times 2.75 \mathrm{~mm}$ (style 511, Labtician Ophthalmics) half-oval silicone sponge was inserted under the preplaced sutures and its edges were sutured, resulting in $360^{\circ}$ of buckle effect.

The Tenon's capsule was not separated from the conjunctiva during the exposure of the sclera, and both remained attached till the end of the procedure. Both the conjunctiva and Tenon's capsule were closed usually in one step by vicryl 6-0 (polyglactin 910) sutures. Laser or cryotherapy was applied during the buckle surgery or shortly after the surgery in cases where it was needed. No laser or cryotherapy treatment was applied at the time of the buckle removal.

\section{Results}

During the study period, 841 SB implants for RRD were performed in our institution, with an annual rate of 40 cases. Forty (4.75\%) were extracted, for an annual rate of 1.9 cases (Table 1$)$. In seven cases $(0.83 \%)$, they were excised because of orbital cellulitis (Table 1). All seven patients had a history of encircling silicone-sponge SB placed for RRD. The mean time from implantation to presentation was 5.7 years (median 14 months, range 3 days to 19 years). The clinical data of the seven patients are summarized in Table 2.

\section{Case I}

A 44-year-old schizophrenic, mentally retarded man presented with a few days of pain and proptosis of his previously

Table I Etiology of 40 cases of scleral buckle removal

\begin{tabular}{ll}
\hline Etiology of scleral buckle removal & Number of cases \\
\hline Infected buckle & 9 \\
Exposed buckle & 9 \\
Orbital cellulitis & 7 \\
Protrusion of buckle & 3 \\
Strabismus & 2 \\
Choroid bulging through sclera & $\mathrm{I}$ \\
Choroidal detachment & $\mathrm{I}$ \\
Microphthalmia & $\mathrm{I}$ \\
Migration of buckle & $\mathrm{I}$ \\
Ocular pain & $\mathrm{I}$ \\
Unknown & 5 \\
\hline
\end{tabular}

operated eye. Seven months earlier, he had undergone vitrectomy and SB procedure for RRD. On presentation, the patient was afebrile with significant ocular movement restriction, with limited duction in all fields of gaze and conjunctival chemosis. Computed tomography (CT) revealed a possible eyelid abscess and an expanded SB. He was treated essentially with intravenous (IV) minocycline and tobramycin. After growth of $S$. aureus, treatment was changed to cloxacillin. The inflammation improved significantly. However, a significant conjunctival granuloma developed 14 months after initial surgery. He underwent buckle removal, conjunctival granuloma excision, vitrectomy, silicone injection, and cataract extraction. He was followed for 12 more months.

\section{Case 2}

A 53-year-old woman with a history of normal-tension glaucoma and past laser trabeculoplasty treatment for both eyes presented with 7 days of pain, eyelid redness, significant chemosis, and proptosis of her eye, operated on for RRD 14 months earlier. Her visual acuity (VA) was 20/120. IV amoxicillin/clavulanic acid treatment was initiated, and buckle removal was undertaken. $S$. aureus was identified. During follow-up, she had cataract surgery and trabeculectomy. She was followed for the next 12 years; her last VA was 20/30.

\section{Case 3}

A 74-year-old man presented with exposed SB implant, purulent discharge, painful eye, and VA of 20/240 10 months after RD surgery with SB and radial sponge repair. IV cloxacillin, cefazolin, and metronidazole were initiated, and an operation for the removal of the buckle was undertaken. S. aureus was identified. He was followed for the next 12 months, with normal findings; his last VA was 20/40.

\section{Case 4}

A 79-year-old man presented with a few days of pain, eyelid redness, significant chemosis and restriction in globe movements, and proptosis of his eye operated on 6 years previously, with $\mathrm{SB}$ and radial sponge for RRD. On presentation, VA was $1 / 24$, and CT revealed air around the buckle laterally with infection infiltration in the orbit. IV cefuroxime and metronidazole treatment was initiated, and an operation for the removal of the two implants was undertaken. S. aureus was identified, and the treatment was changed to cloxacillin according to the infection sensitivity. He was followed for the next 2.5 years and his last VA was 20/70. 
Table 2 Clinical data of the seven patients with orbital cellulitis secondary to scleral buckle

\begin{tabular}{|c|c|c|c|c|c|c|c|c|}
\hline Patient & Sex & $\begin{array}{l}\text { Age, } \\
\text { years }\end{array}$ & Eye & $\begin{array}{l}\text { CT } \\
\text { findings }\end{array}$ & $\begin{array}{l}\text { Operation-infection } \\
\text { interval }\end{array}$ & $\begin{array}{l}\text { Bacteriology } \\
\text { growth }\end{array}$ & $\begin{array}{l}\text { Follow up } \\
\text { (months) }\end{array}$ & Medical background \\
\hline 1 & $M$ & 44 & RE & $\begin{array}{l}\text { OFI, LR } \\
\text { thickening }\end{array}$ & 10 months & $\begin{array}{l}\text { Staphylococcus } \\
\text { aureus }\end{array}$ & 12 & Schizophrenia \\
\hline 2 & $\mathrm{~F}$ & 53 & LE & $\mathrm{OFI}$ & I 4 months & S. aureus & 144 & - \\
\hline 3 & $M$ & 74 & RE & RB abscess & 10 months & S. aureus & 12 & Atrial fibrillation \\
\hline 4 & $\mathrm{~F}$ & 75 & RE & $\begin{array}{l}\text { Orbital } \\
\text { abscess }\end{array}$ & 3 days & $\begin{array}{l}\text { Pseudomonas } \\
\text { aeruginosa }\end{array}$ & 12 & $\begin{array}{l}\text { DM, HTN, atrial } \\
\text { fibrillation, hyperlipidemia }\end{array}$ \\
\hline 5 & M & 79 & LE & OFI & 6 years & S. aureus & 30 & $\begin{array}{l}\text { IHD, hyperlipidemia } \\
\text { spinal stenosis }\end{array}$ \\
\hline 6 & $\mathrm{~F}$ & 85 & LE & RB abscess & 12 years & Citrobacter koseri & 24 & $\mathrm{HTN}$ \\
\hline 7 & $\mathrm{~F}$ & 52 & RE & OFI & 19 years & $\begin{array}{l}\text { Sphingomonas } \\
\text { paucimobilis }\end{array}$ & 30 & $\begin{array}{l}\text { HTN, DM type 2, } \\
\text { hypothyroidism, } \\
\text { hyperlipidemia }\end{array}$ \\
\hline
\end{tabular}

Abbreviations: M, male; F, female; RE, right eye; LE, left eye; OFI, orbital fat infiltration; RB, retrobulbar; IHD, ischemic heart disease; DM, diabetes mellitus; HTN, hypertension; LR, lateral rectus; CT, computed tomography.

\section{Case 5}

A 75-year-old woman presented 3 days following a circular buckling for RRD with pain, eyelid redness, significant chemosis, proptosis, and VA of 20/240. Five years previously, she had had cataract surgery in her right eye. CT revealed orbital abscess (Figure 1). The SB was removed and IV ciprofloxacin and cefazolin treatment was initiated. There was growth of $P$. aeruginosa, and IV ciprofloxacin was continued accordingly. She was followed for the next 12 months and her last VA was 20/30.

\section{Case 6}

An 85-year-old woman presented with 6 hours of left-eye redness and pain. Twelve years earlier, she had had cataract

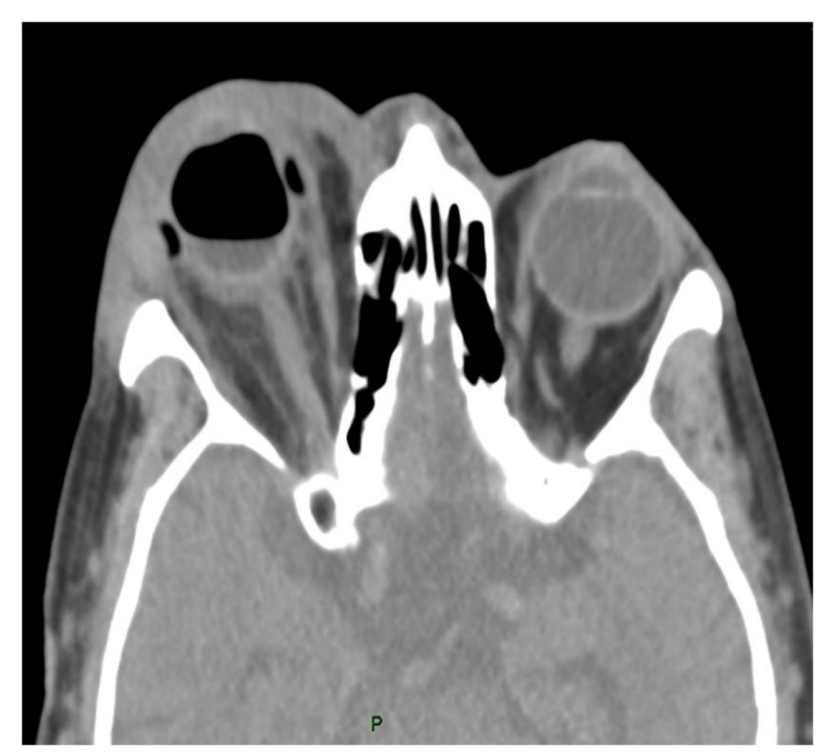

Figure I Patient 5: computed tomography scan of a 75-year-old woman showing right orbital phlegmon, orbital fat infiltration, and proptosis secondary to infected scleral buckle. surgery in her left eye. A few months later, she had RRD in her left eye, which was surgically repaired with SB and radial sponge. She presented with frozen globe, proptosis, ptosis, eyelid swelling, and +2 relative afferent pupillary defect in the left eye. CT revealed exophthalmos, dilatation of the superior ophthalmic vein, and retrobulbar and orbital fat infiltration, but no localized abscess (Figure 2). She responded well to conservative treatment of IV amoxicillin/ clavulanic acid and topical moxifloxacin eye drops. A significant clinical improvement was seen following this treatment. On discharge, her VA was 20/70. Ten months later, she presented with left painful eye and abduction limitation. There was a clinical picture of infected SB and she underwent SB removal. IV ciprofloxacin was initiated. There was a growth of Citrobacter koseri sensitive to the antibiotic. A significant clinical improvement was seen under this treatment. She was followed for the next 24 months, and her last VA was 20/40.

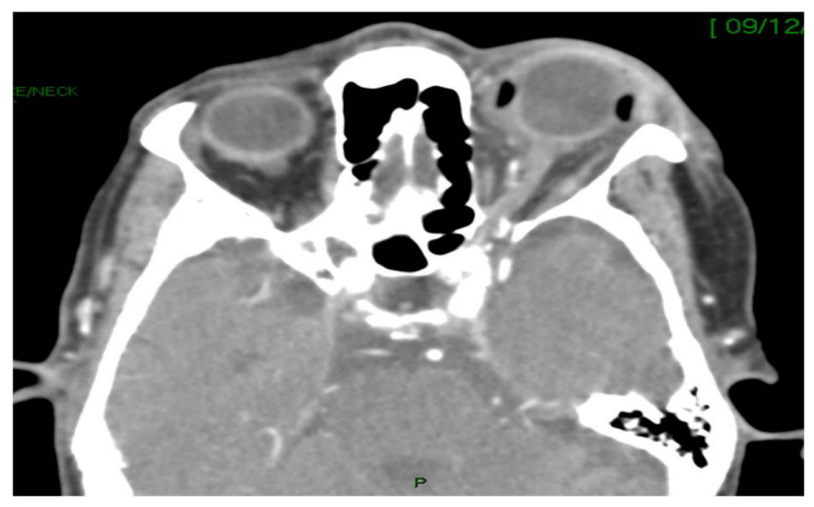

Figure 2 Patient 6: an 85-year-old woman with left orbital phlegmon, dilatation of the superior ophthalmic vein, retrobulbar and orbital fat infiltration, and proptosis secondary to infected silicone-sponge scleral buckle that was inserted 12 years previously, for rhegmatogenous retinal detachment. 


\section{Case 7}

A 52-year-old woman presented with 4 days of right-eye pain with eyelid redness and swelling. Her VA was hand movements before eyes. An SB and radial sponge had been inserted for RRD 19 years previously. She refused to be admitted to the department, and oral amoxicillin/clavulanic acid with topical antibiotics and steroid was initiated. A few days later, there was exacerbation of the pain, limitation with globe elevation, and anterior-chamber reaction with cells +2 . CT revealed infiltration around the SB (Figure 3). IV amoxicillin/clavulanic acid was initiated, and the implant was removed. There was a growth of Sphingomonas paucimobilis sensitive to the entire antibiotics list. She was followed for the next 2.5 years, and her last VA was hand movements.

\section{Discussion}

SB with episcleral solid-silicone or sponge implants was designed especially for the eye. Silicone is a synthetic rubber compound, hydrophobic, and highly stable within a wide temperature range. Silicone is commonly considered the material of choice in SB procedures as it has several advantages: the implants are economical, easy to obtain, soft, biochemically inert, nonallergenic, and generally well tolerated by the body. ${ }^{7,8}$ It was originally meant to be used as a temporary implant, like a cast, but since it is generally well tolerated, it has become a permanent implant. ${ }^{2}$

The first silicone SB was a simple rod-shaped element. ${ }^{9}$ Since then, more than 70 silicone-based implant designs have been developed. Today, a wide range of silicone-implant styles are available for ophthalmic surgeons.

Silicone-sponge buckles are composed of closed-cell foam, which has the same chemical composition as solid silicone implants. With respect to dense implants, silicone sponges are designed to be more elastic and to produce a more even

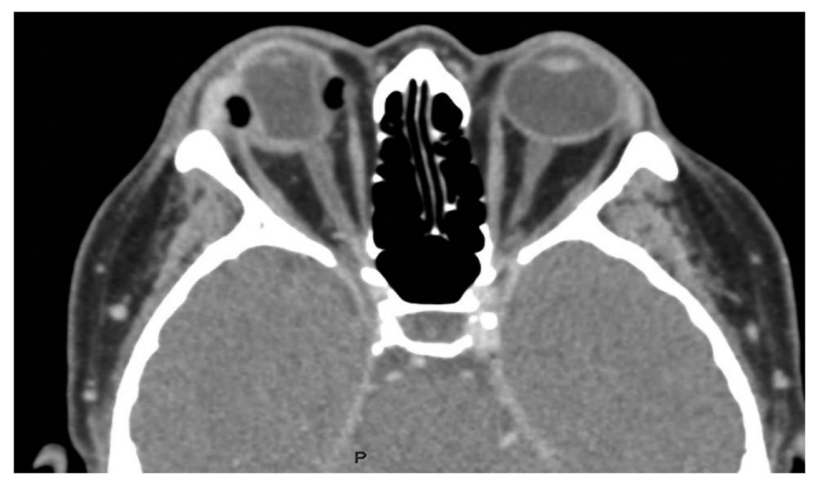

Figure 3 Patient 7: a 52-year-old woman with right orbital cellulitis, orbital fat infiltration, and proptosis secondary to infected silicone-sponge scleral buckle that was inserted 19 years previously for rhegmatogenous retinal detachment. buckling effect, which usually increases postoperatively. ${ }^{10}$ The sponges can be impregnated with antibiotics to limit the bacterial colonization of the implant. ${ }^{11}$ In most cases, silicone sponges are used as episcleral implants, but they can also be placed under scleral flaps if desired.

The smoothness of silicone material and the rounded contour of the implant lead to the development of a tough, collagenous capsule around the implant. ${ }^{12}$ At first vascularized, the capsule becomes avascular and translucent over time. In episcleral implants, the capsule seals off the buckle, thereby helping to minimize the risk of later infection. Dense silicone does not allow tissue ingrowth, and can easily be taken out in one piece without significant trauma if removal becomes necessary. ${ }^{13,14}$ The main advantages and disadvantages of the various silicone buckles are presented in Table 3.

SB can occasionally induce long-term complications. ${ }^{15,16}$ The rates of extraocular SB infection as clinically diagnosed are reported to be $0.5 \%-5.6 \% .^{2}$ Typical signs and symptoms include irritation, discomfort, discharge, chemosis, and injection. Less common signs of infection include intraocular inflammation, ${ }^{17}$ scleritis, ${ }^{18}$ and conjunctival granuloma. ${ }^{19}$

SB infection is affected by the surgical technique, different synthetic materials of scleral explants, duration of surgery, size, and position of the buckle., ${ }^{4,20,21}$ Removal of the implant as a result of infection has been reported to be most commonly seen with the use of a silicone sponge $(9 \%)$ or hydrogel implant (1.3\%), and least commonly encountered with a silicon rubber band $(0.6 \%){ }^{21}$ The most commonly reported organisms in SB infections are coagulase-negative staphylococcal skin flora, presumably from the patient's eyelids, and in acute-onset scleral explant infections, S. aureus, Proteus mirabilis, and $P$. aeruginosa are commonly identified. ${ }^{20}$

Microbiology trends in these reports vary slightly based on location. More recent series have documented a rise in mycobacterial and polymicrobial infections. ${ }^{22,23}$ In our series, there was one case with acute infection with P. aeruginosa infection, while four other cases 10 months to 6 years following the operation were induced by $S$. aureus infection.

$S$. aureus is a very common cause of anterior blepharitis and external eye inflammation that can spread to the orbit from the skin. Staphylococcal organisms are able to produce toxins that promote their virulence, which leads to the inflammatory response seen in orbital cellulitis. ${ }^{24}$

Russo and Ruiz classified 31 cases of silicone-sponge infection as occurring either early ( $2-8$ weeks) or late ( 2 months -4 years) ${ }^{20}$ They hypothesized that early infections, presenting with acute, active signs, were caused by contamination at the time of surgery, and that late 
Table 3 The main advantages and disadvantages of the various silicone buckles

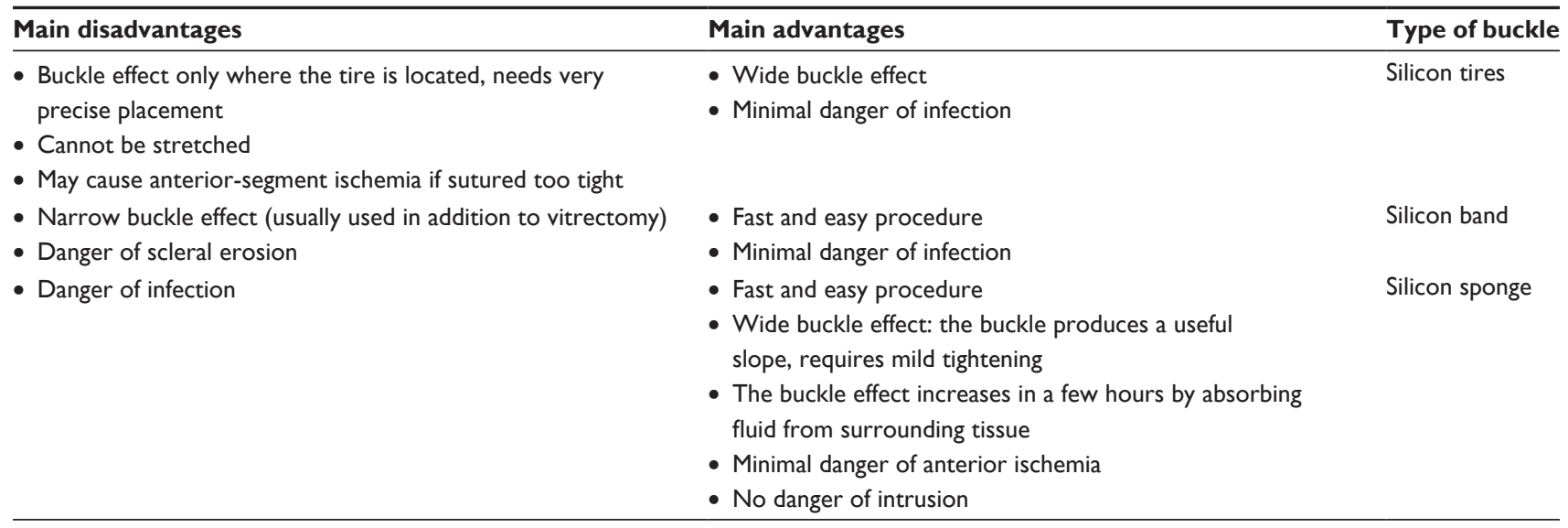

infections, presenting with chronic, indolent signs, were from mechanically extruded SBs that were secondarily infected. Four cases in our series were late infections, and all were contamination by $S$. aureus.

Biofilm has been postulated to cause SB-associated infections by a mechanism of persistence. Biofilm is an extracellular polysaccharide or glycocalyx that bacteria secrete to maintain their adherence on prosthetic devices, such as urinary catheters and heart valves. ${ }^{25}$ In a study by Holland et al silicone sponge and solid silicone contained biofilm on their surface. The biofilm extended $5 \mathrm{~mm}$ from the cut end into the pores. ${ }^{26}$ It has been postulated that bacteria can be inoculated at the time of SB surgery. ${ }^{6}$

The scleral abscess and orbital infection rate have declined significantly with the development of modern-day silicone solid and sponge implants. In 1965, the rate of scleral abscess after SB was reported to be $4 \%,{ }^{2}$ while in our series the rate was $0.83 \%$. It is likely that both the trend of replacing diathermy with cryotherapy and subretinal drainage, along with better antiinfection precautions, are responsible for this decrease..$^{2,27}$ Folk et al reported scleral abscesses in $0.58 \%$ of 4,480 patients who had SB performed with cryotherapy and no diathermy. ${ }^{28}$

To conclude, sponge SBs are safe in the short and long term. However, infection may occur acutely or even years after the operation. Hence, long follow-up is necessary, and every ocular symptom should be investigated and suspected to be a buckle infection and orbital cellulitis.

\section{Disclosure}

The authors report no conflicts of interest in this work.

\section{References}

1. Heimann H, Bartz-Schmidt KU, Bornfeld N, Weiss C, Hilgers RD, Foerster MH. Primary pars plana vitrectomy. Techniques, indications, and results. Ophthalmologe. 2008;105(1):19-26. German.
2. Tsui I. Scleral buckle removal: indications and outcomes. Surv Ophthalmol. 2012;57(3):253-263.

3. Roldan-Pallares M, del Castillo Sanz JL, Awad-El Susi S, Refojo MF. Long-term complications of silicone and hydrogel explants in retinal reattachment surgery. Arch Ophthalmol. 1999;117(2):197-201.

4. Schwartz PL, Maris PJ, Maris CE. Silastic sponge implants in retinal detachment surgery. Ann Ophthalmol. 1981;13(9):1089-1092.

5. Chaudhry NA, Tabandeh H, Rosenfeld PJ, Miller D, Davis J. Scleral buckle infection with ciprofloxacin-resistant Pseudomonas aeruginosa. Arch Ophthalmol. 1998;116(9):1251.

6. Asaria RH, Downie JA, McLauglin-Borlace L, Morlet N, Munro P, Charteris DG. Biofilm on scleral explants with and without clinical infection. Retina. 1999;19(5):447-450.

7. Lincoff HA, McLean JM, Nano H. Scleral abscess. I. A complication of retinal detachment. Buckling procedures. Arch Ophthalmol. 1965;74(5): 641-648.

8. Schepens CL, Okamura ID, Brockhurst RJ, Regan CD. Scleral buckling procedures. V. Synthetic sutures and silicone implants. Arch Ophthalmol. 1960;64:868-881.

9. Girard LJ, McPherson AR. Scleral buckling. Full thickness and circumferential, using silicon rubber rodding and photocoagulation. Arch Ophthalmol. 1962;67:409-420.

10. Brown DM, Beardsley RM, Fish RH, Wong TP, Kim RY. Long-term stability of circumferential silicone sponge scleral buckling exoplants. Retina. 2006;26(6):645-649.

11. Arribas NP, Olk RJ, Schertzer M, et al. Preoperative antibiotic soaking of silicone sponges. Does it make a difference? Ophthalmology. 1984;91(12):1684-1689.

12. D'Hermies F, Korobelnik JF, Caputo G, et al. Encapsulation of scleral buckling materials. A study of sixty specimens. Ophthalmology. 1998;105(6):1079-1086.

13. Lindsey PS, Pierce LH, Welch RB. Removal of scleral buckling elements. Causes and complications. Arch Ophthalmol. 1983;101(4):570-573.

14. Wiznia RA. Removal of solid silicone rubber exoplants after retinal detachment surgery. Am J Ophthalmol. 1983;95(4):495-497.

15. Lincoff H, Stopa M, Kreissig I, et al. Cutting the encircling band. Retina. 2006;26(6):650-654.

16. Deokule S, Reginald A, Callear A. Scleral explant removal: the last decade. Eye (Lond). 2003;17(6):697-700.

17. Oz O, Lee DH, Smetana SM, Akduman L. A case of infected scleral buckle with Mycobacterium chelonae associated with chronic intraocular inflammation. Ocul Immunol Inflamm. 2004;12(1):65-67.

18. Rich RM, Smiddy WE, Davis JL. Infectious scleritis after retinal surgery. Am J Ophthalmol. 2008;145(4):695-699.

19. Nielsen JS, Blatt S, Perlman JI, Gieser RG. Clinicopathologic case report: scleral buckle associated nontuberculous mycobacterial scleritis. Semin Ophthalmol. 2004;19(3-4):101-104. 
20. Russo CE, Ruiz RS. Silicone sponge rejection. Early and late complications in retinal detachment surgery. Arch Ophthalmol. 1971;85(6):647-650.

21. Roldán-Pallarés M, Avila MI, Refojo MF. The use of boric acid solution to help in the removal of biodegraded Miragel episcleral buckles. Retina. 2005;25(1):90-93.

22. Pathengay A, Karosekar S, Raju B, Sharma S, Das T. Microbiologic spectrum and susceptibility of isolates in scleral buckle infection in India. Am J Ophthalmol. 2004;138(4):663-664.

23. Smiddy WE, Miller D, Flynn HW Jr. Scleral buckle removal following retinal reattachment surgery: clinical and microbiologic aspects. Ophthalmic Surg. 1993;24(7):440-445.

24. Nakata K, Inoue Y, Harada J, et al. A high incidence of Staphylococcus aureus colonization in the external eyes of patients with atopic dermatitis. Ophthalmology. 2000;107(12):2167-2171.
25. Gristina AG. Biomaterial-centered infection: microbial adhesion versus tissue integration. Science. 1987;237(4822):1588-1595.

26. Holland SP, Pulido JS, Miller D, et al. Biofilm and scleral buckleassociated infections. A mechanism for persistence. Ophthalmology. 1991;98(6):933-938.

27. Lincoff $\mathrm{H}$, Nadel A, O'Connor P. The changing character of the infected scleral implant. Arch Ophthalmol. 1970;84(4):421-423 passim.

28. Folk JC, Cutkomp J, Koontz FP. Bacterial scleral abscesses after retinal buckling operations. Pathogenesis, management, and laboratory investigations. Ophthalmology. 1987;94(9):1148-1154.
Clinical Ophthalmology

\section{Publish your work in this journal}

Clinical Ophthalmology is an international, peer-reviewed journal covering all subspecialties within ophthalmology. Key topics include: Optometry; Visual science; Pharmacology and drug therapy in eye diseases; Basic Sciences; Primary and Secondary eye care; Patient Safety and Quality of Care Improvements. This journal is indexed on

\section{Dovepress}

PubMed Central and CAS, and is the official journal of The Society of Clinical Ophthalmology (SCO). The manuscript management system is completely online and includes a very quick and fair peer-review system, which is all easy to use. Visit http://www.dovepress.com/ testimonials.php to read real quotes from published authors. 